tion of cases in which albumen has been believed to occur in the urine, both in disease and apparent health, has been stated at too high a figure by numerons observers, whose results in many instances are not worth the paper on which they are written. If the cases in which mucin alone has been mistaken for albumen were excluded, the proportion would be considerably reduced. Nevertheless, from the frequency with which we find albumen and an increase of mucin together in the urine, this diminution in the cases of undoubted albuminuria would not be so great as otherwise might have been expected.

The most interesting question that remains is as to the origin of the urinary mucin and its significance in increased quantity in the urine. Hitherto the prevalent idea has been that it is derived chiefly, if not solely, from the mucous membrane of the bladder and the rest of the urinary tract. But it can hardly be supposed that the urine in jaundice and some other pathological states can be so stimulating to the urinary mucous membrane as to cause that considerable increase of mucin which is found in that fluid in these conditions. Above all, if there be a considerable increase of mucin in the urine in many cases of albuminuria we are with our present knowledge quite at a loss to account for it. It seems to me impossible to explain its variations in the urine on any other supposition than that it is largely derived from the metabolic processes of the epithelium of the renal tubules themselves. Dr. Ralfe seems to have supplied just the very link which was wanting in our knowledge as to the causation of various forms of functional albuminuria by the suggestion that they are mostly due to derangements of the metabolic activity of the renal cellsthat function by which they separate albuminous constituents from the blood, and either appropriate and convert them for their own nutrition, or decompose them into urea and other products. When this function is inadequately performed, either from excess of work thrown on healthy epithelium, or from any cause tending to impair the functional activity of this structure, albuminuria may result. ${ }^{3}$ And if mucin be a product of this metabolism we can at once see that the same circumstances which produce albuminuria would also lead to increased mucinuria. If this view should prove to be well founded, it would give a different complexion to many of the problems involved in albuminuria. Here it may be of interest to recall the fact, first pointed out by Dr. Finlayson of this city in 1874, that tube casts have been found in jaundiced urines in the absence of albumen. When we consider that such urines are invariably rich in mucin, however, the oc currence of tube casts in them may be of the highest significance, and lends support to the supposition here advanced. It seems almost certain that increased mucinuria is not only a frequent conconitant of albuminuria, but may be the precursor of the latter, and therefore in itself a danger signal. Hence heat with acetic or picric acid, even when it gives a result which may be only mucinous, really reveals a morbid condition, for the same result is notobtained in strictly normal urine. Defective metabolism of the renal epithelium may, in its minor degrees, show itself only by increased mucinuria, and in a more advanced stage by albuminuria. There is a certain harmony between this view and that of Senator and Posner, for this first stage would only be an increase of a physiological phenomenon.

Partick.

\section{CASE OF ADDISON'S DISEASE WITHOUT PIGMENTATION.}

\section{By H. E. COUNSELL, L.R.C.P. LoND.}

G. B-, aged twenty-seven, a carter, came to me about September last, complaining of pains after neals, with feelings of nausea, but no actual sickness. For this a tonic was prescribed, with benefit. He used to appear again and again with the same symptoms, which were so far relieved that in November and December he was not seen at all, and it was not until January that symptoms once more became so severe that two or three days' holiday were taken at a time; feelings of great depression, accom panied by actual, though occasional, sickness, then develop. ing. I then obtained further particulars concerning him.
The family history was good; no phthisis; no history of any hereditary disease. No illness, but had been until five years ago very intemperate, his usual drink being beer. Married, and has four children, but has been completely impotent for the last two years. Patient was a big, welldeveloped man, with dark-brown hair and light-brown eyes. On January loth I examined him in bed. He told me that since the commencement of his illness he had lost 2 st. in weight, and that since Christmas he had become short of breath, especially on going upstairs. Nothing was made out from the examination, except that the liver dulness was small, and that there was considerable tender. ness over the epigastrium and under the ribs on the right side. He had also a slight yellow tinge, but the conjunctivæ were not jaundiced. Urine normal; sp. gr. 1020. Under the same treatment he picked up and got about his work again until February. He then became much weaker, and sick. ness became more constant. Nothing could be learnt from his vomit, which consisted simply of undigested food and bile. His bowels were open normally except for a little straining sometimes. On Feb. 6th he passed what he described as a piece of "rotten liver" in his motion, but it was not saved for examination. By the 12 th he became so weak and faint that he took to his bed entirely, and the vomiting became almost constant after taking any food. He complained of acute pains in the abdomen, sometimes referred to the umbilicus, sometimes to the epigastrium. There was no distension, the abdomen being rather retracted. On the 15th I saw the patient in consultation with Dr. Ticehurst of Petersfield. The patient was then very weak; pulse could just be felt, 120; hands cold; and he was giddy on attempting to sit up in bed. The pain in the abdomen was referred to the epigastrium, where there was also tenderness. The liver dulness was much diminished, being only one inch and a half in the nipple line. Three things were discussed as probabilities: 1. Acute yellow atrophy of the liver. 2. Growth coming forwards involving deep nerve plexuses and pressing upon duodenum. 3 Although the skin was not pigmented, Addison's disease. On the 16th there was a great change for the worse; pulse sometimes could not be felt; he vomited every hour nasty black stuff, which sometimes looked as though it contained altered blood. His mental condition was cloudy; he was restless and constantly yawning. No pain in head; no failure of sight; fed by enemata. On the 17th he was pulseless, very thirsty, constantly retching, and had passed no urine for twenty-four hours; tongue furred and dry; features pinched and drawn-in fact, he had all the symptoms of acute abdominal collapse. In the right iliac fossa an elongated mass could be felt, which rolled under the finger, and seemed to bear some resemblance to an intussusception. Nothing could be felt per rectum. A fourth possible explanation of the symptoms now suggested itself-the strangulation, through the foramen of Winslow or diaphragm, of a piece of intestine high up, thus preventing general distension. Addison's disease was again discussed, so also was acute yellow atrophy, which, however, was completely negatived from absence of jaundice and delirium; so that the diagnosis seemed to lie between Addison's disease and an acute strangulation high up in the intestinal canal. For the former affection there was the chronic history, wasting, breathlessness, sickness, collapse-against, the present acuteness of the symptoms, the complete absence of bronzing either of the skin or mucous membranes, the general appearance of the patient, which was exactly like a person suffering from intestinal obstruction. For a strangulation there was the acute history of the past few days and the appearance of the patient, suppression of urine, and constant vomiting -against, a somewhat vague history that on the 15th a dose of salts had acted after great straining, bringing away a hard motion and a quantity of material like coffee grounds, together with the long history of illness and wasting. On the morning of the 18 th the patient died. A necropsy was made the same day. Through the very limited abdominal incision which was allowed the whole intestinal tract was examined and found practically healthy. No peritonitis. A retro-cæcal pouch was discovered, which contained the vermiform appendix distended with mucus. The suprarenal capsules were next removed, and one of them was sent to Guy's for microscopic examination. It weighed a drachm and a quarter, was larger than normal, and its surface bossy, from large white deposits in its substance. On longitudinal section these were found scattered through the medulla and cortex of the organ. They varied in size from 
a pea to a cob-nut, and resembled in appearance the caseous material found in lymphatic glands. Several slides were examined by Neelsen's method for tubercle bacilli, but without success. Under the microscope these masses were found to be almost entirely caseous, and stained badly. They were surrounded by a narrow zone of small cell tissue, in which nany giant cells were seen. There can be little doubt doubt they were of a tubercular nature. There is a general impression that tubercle bacilli are not found in Addison's disease, but this is not the fact. However, it is admitted by the authorities that they are difficult to find, and the same is true of tubercle in bones and joints.

I have called this a case of Addison's disease without pigmentation, not implying by that title that I look upon it as a distinct form of the disease, but simply a case that ran such a rapid course that pigmentation had no time to develop, and have published it to show how hard the diagnosis of such an early case must be, and the many points for discussion which may be raised in its progress. Impotence I do not find mentioned anywhere as a symptom of the disease, but it is certainly one which one would expect to find in such a supremely "nervous" disease as Addison. I have to thank my friend, Mr. Targett, for kindly examining and reporting on the condition of the suprarenals, and $\mathrm{Mr}$. Dunn for his assistance during the progress of the case.

Liss, Hants.

\section{TYPHOID FEVER; PERFORATION (?) ; LOCAL PERITONITIS ; OPERATION ; RECOVERY.}

\section{BY JOHN W. TAYLOR, F.R.C.S.,}

SURGEOV TO THE BIR IINGHAM AYD MIDLAND HOSPITAL FOR WOMEN COYSULTING SLRGEON TO THE WOLVERHAMPTON HOSPITAT FOR WOMEN, ETC.

THIs patient was under the care of Dr. Walter Garman of Wednesbury, and I am indebted to him for all the early history of the case.

Richard $\mathrm{C} \_$, aged thirty-three, single, a furnace worker in a tube manufactory, was taken ill about the middle of August, 1888, and had to leave his work the first week in September, when Dr. Garman was called to attend him. During this attendance the patient passed through the ordinary course of a severe attack of typhoid fever, in which the signs and symptoms of this disease-abdominal pain and tenderness, diarrhoea, the rose rash, and the typical temperature--were all well marked. Other cases of typhoid fever were occurring in the same neighbourhood about this date. From this attack the patient began slowly to recover, and it was thought that he had become convalescent. A relapse, however, occurred, and during this relapse the symptoms became much more acute and dangerous than they had previously been. The abdomen was distended and extremely tender, and at one period so marked was the collapsed condition of the patient that perforation was suspected. The patient lived through this time of severest danger, and then it was noticed that a tumour was forming in the upper part of the abdomen, between the sternum and the umbilicus. This steadily increased in size, and as it grew the patient began to suffer from attacks of hæmatemesis. These became alarming, on one or two occasions as much as a pint of blood being vomited. It was at this stage of his disease that I saw the patient with Dr. Garman, our consultation being held on Dec. 12th, and the perforative stage of the disease-if such it was-having occurred some ten days previously.

A prominent rounded swelling occupied the epigastric and upper umbilical regions. It was continuous with the liver. The latter was not displaced upwards by the tumour. On palpation a sense of deep fluctuation, or rather that feeling of elasticity which is significant of distant fluid, was plainly perceptible. I diagnosed the enlargement to be cystic, involving the left lobe of the liver, and advised an early operation. This was performed two days later, another attack of hæmatemesis having occurred the night previously. The steps of the operation done were exceedingly simple. An incision was made in the middle line between the sternum and umbilicus, and gradually deepened until the fluid was reached. The peritoneum in this situation was absolutely adberent, and we had to cut through what appeared to be the thinned edge of the left lobe of the liver before reaching the cyst. About three pints of brown, slightly turbid fluid were evacuated. A finger inserted into the cavity which had contained this collection found it sharply bounded by a transverse line below; its height and depth were out of reach. Owing to the adhesions it is impossible for me to state the exact situation and relations of the cyst. It appeared to come towards the surface between the liver and the stomach, and perhaps it may have had direct connexion with the lesser sac of the peritoneum. A large rubber drainage tube was left in the cyst and the incision closed around it. The patient made a rather slow but steady convalescence, and finally a complete recovery. On one occasion only did he have any return of the hæmatemesis. This was after eating rather heartily of fowl and pigeon-pie some ten days after his operation. On account of this all solid food was stopped for some time longer, until Dr. Garman felt satisfied that he was able to take it without danger.

The interest of the case is of course much more clinical than surgical. Typhoid fever is, unfortunately, still so common that it is very possible the foregoing history may some day be repeated. If so, the record of this case may be of service. The operation was performed in one of the little houses of a court at Wednesbury. No trained nurse was available except at the time of operation, and the patient has mainly to thank the nursing of his sister and the careful attention of Dr. Garman for his recovery. Whether the true sequence of events was that which appears in the title of this paper cannot be absolutely known. It appears to me to be the most rational explanation of the history I have related.

Birmingham.

\section{Clintital allots:}

MEDICAL, SURGICAL, OBSTETRICAL, AND THERAPEUTICAL.

\section{A CASE OF INTUSSUSCEPTION OF NINE DAYS' DURATION SUCCESSFULLY TREATED BY INFLATION.}

By T. GRant Langhorne, M.R.C.S., L.R.C.P.

THE history of the case is as follows. On Saturday afternoon, Jan. 25th, the mother noticed that her infant, nine months old, was very sick, throwing up its milk as soon as it swallowed it, and also that it had diarrhoa very badly. She informed me that the child was perfectly well in the morning, crawling about the floor as usual. She gave it a powder, but the next day, being no better, she took it to the chemist, who gave her some powders. The sickness and purging, however, got worse, and the child strained very much, but nothing passed but blood and slime. On Thursday, the 30th, she sent for me, but I was away in the Bush, and did not see the child till Sunday about 11 P.M. I found the child in her mother's arms, with its legs drawn up, and evidently in great pain. The face was pinched and white and her feet and hands quite cold, although the temperature of the room was $85^{\circ} \mathrm{F}$. The abdomen was swollen and tympanitic and very tender. Tongue dry and glazed. She was sick every few minutes and constantly straining, nothing but blood and mucus passing. On introducing my finger into the rectum I fancied I could feel something come down when she strained, so I gave her chloroform, and could then distinctly feel the invaginated gut with a wellmarked dimple on its anterior surface. My other hand on the abdomen made out a well-defined sansage-shaped tumour in the left iliac fossa. The child seemed to be dying, and the parents were very anxious that something should be done, so I determined to try to replace by means of inflation, but with, as I thought, no hope of success, considering the length of time the gut had been invaginated. I took an ordinary pair of bellows, wrapping a piece of oiled rag round the nozzle, and, keeping one hand on the abdomen, slowly distended the rectum. After about two or three minutes' gentle blowing. I felt the tumour in the abdomen suddenly disappear. Making sure the intestine had ruptured, I withdrew the bellows and introduced my 